\title{
El sufragio femenino en El Salvador: contextos nacionales e internacionales
}

\author{
Women's SUfFrage in El SAlvador: NATIONAL AND INTERNATIONAL \\ CONTEXTS
}

Sonia Priscila Ticas

Linfield University, Oregon, EE. UU. http://orcid.org/0000-0001-5272-5941

sticas@linfield.edu

Resumen: El presente trabajo arroja luz sobre los contextos nacionales e internacionales que incidieron en la lucha por la ciudadanía femenina en el período entre 1920 y 1950 en El Salvador, marcado por la presencia de gobiernos militares. Paralelamente a las acciones de algunas figuras destacadas en el foro nacional, se consideran las gestiones en la Comisión Interamericana de Mujeres que feministas salvadoreñas y delegados gubernamentales realizaron en el marco de los congresos panamericanos. $\mathrm{Al}$ trazar la historia del sufragio en El Salvador, se descubre un tira y afloja que puso en jaque el reconocimiento de la ciudadanía femenina. Concluimos que los gobiernos de turno, en un país donde la democracia solo ventilaba en escasos momentos, promovieron el voto femenino cuando parecía políticamente ventajoso, pero lo descartaron para salvaguardar su hegemonía frente a nuevos votantes.

Palabras Clave: sufragio femenino, El Salvador, Comisión Interamericana de Mujeres, martinismo. 
AвSTRACT: This article sheds light on the national and international contexts that marked the struggle for recognition of women's citizenship during the 1920's through the 1950's in El Salvador. In tandem with the activism of key figures at the national level, the advocacy of representatives to the International Commission on Women as well as the actions of government delegates in the Panamerican Conferences is analyzed. When tracing the history of suffrage in El Salvador an oscillation that threatened the recognition of women's citizenship is evidenced. In the end, the governments in power, in a country where democratic respite was brief, promoted women's suffrage only when it was politically advantageous yet tossed it aside when new voters might threaten their hegemony.

KeYwords: women's suffrage, El Salvador, Interamerican Commission of Women, martinismo.

\section{INTRODUCCIÓN}

En países con pocas garantías democráticas, como El Salvador de la primera mitad del siglo XX, se tendría que recorrer un largo camino para crear consciencia entre diversos sectores sociales y políticos sobre la injusticia arraigada en la negación de derechos políticos a sus mujeres. Los gobiernos de turno solo llegaron a considerar el asunto en escasas ocasiones, cuando parecía beneficioso contar con mujeres ciudadanas. El presente trabajo propone dilucidar los contextos nacionales e internacionales que incidieron en la lucha por la ciudadanía femenina en el período entre 1920 y 1950 en El Salvador. Paralelamente a las acciones de algunas feministas destacadas que intentaron liderar un movimiento sufragista en el país, se consideran las gestiones realizadas en el seno de la Comisión Interamericana de Mujeres (CIM) y de delegados salvadoreños en el marco de los congresos panamericanos. Al trazar esta historia se descubre un conflicto que puso en peligro el reconocimiento de la ciudadanía femenina. No obstante, sin estos dos frentes, el nacional e internacional, la lucha por la obtención del voto femenino y la victoria en contra de las restricciones que distintos gobiernos impusieron al ejercicio pleno de la ciudadanía no habría sido posible en 1950. 
EL CONTEXTO NACIONAL E INTERNACIONAL EN LA DÉCADA DE I 920

Cuando en abril de 1922 un grupo de mujeres fundó la primera organización sufragista del país, Confraternidad de Señoras de El Salvador, lo hicieron forjando lazos con "La Liga de mujeres neoyorquinas" (Cañas Dinarte, "El largo camino" párr. 25). Es evidente que desde esta incipiente movilización las salvadoreñas entendían que necesitarían del respaldo internacional para darles más peso a sus demandas. La Confraternidad la conformaban principalmente damas de clase media que desde inicios del siglo venían abogando por una educación femenina más amplia y cambios al Código Civil que les permitieran a sus congéneres una mayor libertad de acción y autonomía económica ${ }^{1}$. Se les había otorgado el sufragio -aunque con restricciones por edad, estado civil y nivel económico- a las salvadoreñas, guatemaltecas y hondureñas en la Constitución Federal el 12 de septiembre de 1921. No obstante, el proyecto de unión centroamericana se derrumbó en febrero de 1922, dejando desamparado al selecto grupo de mujeres autorizadas para votar. Las sufragistas salvadoreńas, conocidas por apoyar el unionismo, abanderaron la causa sufragista para sostener el sueńo de unión regional. Tal organización la lideraron María Solano Álvarez de Guillén Rivas y Victoria Magaña de Fortín, ambas del occidente del país, donde por décadas existió un acendrado patriotismo femenino enfocado en la unión (ibid.).

El férreo control del régimen oligárquico de los Meléndez-Quiñonez no permitió que floreciera su movimiento. Es más, al afiliarse con el partido de la oposición, cientos de mujeres que el 25 de diciembre de 1922 marchaban por las calles de San Salvador fueron ametralladas por el aparato represivo de la oligarquía. La brutal represión hacia los opositores del sistema las obligó a buscar otras formas de participación social como las luchas contra el alcoholismo y la prostitución, temas que a su vez formaban parte del ideario unionista (Casaús Arzú 185-7; Alvarenga 226-9).

1 Para un recuento de las leyes asociadas con el matrimonio y la sexualidad en los códigos civiles en Centroamérica véase el artículo de Eugenia Rodríguez Sáenz, "Controlando y regulando el cuerpo, la sexualidad y la maternidad de las mujeres centroamericanas (siglo XIX e inicios del siglo XX)". Cuadernos intercambio sobre Centroamérica y el Caribe, Vol, 11, No. 2, (julio-diciembre, 2014), 233-258. 
En el foro internacional donde se empezó a discutir una plataforma de reformas que garantizaran distintos derechos femeninos, y en los años que siguieron a su organización, las salvadoreñas vieron abrirse una brecha en su lucha por la igualdad de derechos. La escritora Alice Lardé de Venturino, por ejemplo, asistió en 1925 al Congreso Internacional Femenino en Buenos Aires pronunciándose a favor de que la mujer casada con un extranjero no perdiera su nacionalidad, como ocurría en El Salvador y en otras naciones del continente. Asimismo, concurrió al congreso que se celebró a favor de la paz en Río de Janeiro en 1927 (Cañas Dinarte, Diccionario 228). Esta participación posicionó a las salvadoreńas para colaborar con la Comisión Interamericana de Mujeres (CIM) en la siguiente década.

La presencia de delegadas femeninas en los congresos panamericanos había sido acordada en la V Conferencia de Estados Americanos en Chile en 1923 (CIM/OEA, "A Brief History" 2). Al formarse la CIM a partir de la VI Conferencia celebrada en la Habana en 1928, la sufragista salvadoreña María Solano Álvarez de Guillén Rivas se convirtió en una de las primeras seis integrantes que pusieron en marcha la organización que tendría a su cargo la principal abogacía a favor de los derechos femeninos a nivel continental (CIM/OEA, History 5).

Los encuentros feministas panamericanos, desde el que se organizó en Baltimore, Maryland, en 1922, tenían como meta principal crear alianzas entre diversas organizaciones femeninas y establecer una agenda común al continente (CIM/OEA, "A Brief History" 2). Algunas feministas norteamericanas, sin embargo, enfocaban la promoción del sufragio, mientras que las latinoamericanas buscaban reformas sociales más amplias, así como la promoción de la paz hemisférica (Threlkeld 816-9). La expansión de oportunidades educativas, por ejemplo, tomaba prioridad sobre la lucha por la ciudadanía en distintos países latinoamericanos, pues las líderes feministas veían la necesidad apremiante de mejorar las condiciones de vida de sus congéneres antes de convertirlas en votantes (Miller 86-7). La historiadora Asunción Lavrin explica que algunas de estas mujeres sostenían que el voto en sí no garantizaba otras reivindicaciones, aunque se esperara lo contrario (6).

Para las unionistas centroamericanas el sufragio era significativo, pues creían fervientemente que votando por candidatos unionistas podrían asegurar la unión. Sin embargo, abogaban también por la expansión 
educativa para que al lograr el voto se contara con mujeres preparadas para los deberes ciudadanos (Magańa de Fortín 35). Estas prioridades encajaban con las ideas liberales sobre la educación que permeaban el pensamiento unionista-teosofista de la época (Casaús Arzú 181-7). En el ideario político dominante liberal, la educación femenina solía fomentarse para promover el rol de la madre cívica, es decir, la encargada de educar a los hijos varones para convertirlos en ciudadanos dignos (Uriarte 201; Vásquez Monzón 110). Las unionistas negociaron estas expectativas sociales insistiendo en que su rol ciudadano también sería de gran beneficio en la crianza de los nuevos ciudadanos que les urgían a las naciones centroamericanas.

Los cambios culturales vertiginosos obviamente causaban gran incomodidad en las sociedades patriarcales y estas feministas unionistas eran conscientes de que debían operar con cautela dentro de lo que las normas sociales y culturales exigían. Más que suscitar cambios inmediatos en el país, las alianzas que forjaron en el marco internacional contribuyeron a mantener la cuestión de los derechos femeninos en el foro público para seguir creando mayor conciencia. Las salvadoreñas, como sus homólogas latinoamericanas, albergaban la esperanza de que al convertirse en signatarios de acuerdos internacionales sus respectivos gobiernos cambiarían las leyes nacionales relativas a los derechos civiles (Miller 82).

Prudencia Ayala y las luchas sufragistas en torno a las elecCIONES DE I93 I

Hacia finales de la década de 1920 soplaban vientos políticos más favorables para el sufragismo femenino en El Salvador. Con el gobierno de Pío Romero Bosque (1927-1931), que acabó con trece años de oligarquía, se instituyeron varias reformas democráticas que culminarían con la primera elección presidencial libre en enero de 1931 (Alvarenga et al. 112). Es en este contexto que comenzó a darse una nueva coyuntura que permitiría la reincidencia de las sufragistas en el foro público nacional. Al lado de las mujeres de la clase media, también se elevaron otras voces.

Una de las sufragistas más consecuentes de esa época fue Prudencia Ayala, una mujer de la clase trabajadora y acendrada unionista, quien 
desde las páginas de los periódicos del occidente del país publicaba proclamas abogando por la igualdad de derechos femeninos. En el ideario político de Ayala, la ciudadanía femenina era vital para sostener la unión de los pueblos del istmo. Por ello su voz ardió en los escenarios unionistas y en sus escritos, publicados bajo los títulos Inmortal, amores de loca (1925) y Payaso literario en combate (1928). En dichos textos, Ayala difundió su pensamiento unionista-feminista dando cuenta de su trayectoria en esta lucha ${ }^{2}$.

A fines de la década de 1920, Ayala se encontraba en Guatemala formando su propio contingente femenino y propagando sus ideas sobre el feminismo centroamericano e internacional a través de su semanario Redención Femenina. Al ver que el mandatario salvadoreńo se aprestaba a abrir el sistema político convocando a candidatos para las elecciones presidenciales de enero de 1931, volvió para emprender una campańa que la convertiría en un ícono de los derechos políticos:

Tomando en cuenta la libertad [que] ha surgido en mi querida tierruca y no queriendo que el sexo femenino permanezca fuera de la ley restringida de los derechos de ciudadano, lanzo mi candidatura para Presidente de la República, inspirada en la justicia de un gobierno mixto que identifique la soberanía de la nación en los dos sexos (Archivo, "Resulta una candidata").

Ayala sacudió de manera novedosa a la sociedad salvadoreña, instando a sus contemporáneos a imaginar a la mujer con plenitud de derechos no solo como votante, sino también como dirigente de la nación. Así pues, hizo campaña con el respaldo del Partido Unionista pese que a las mujeres no se les reconocía la ciudadanía. Como lo harían en otros países sus homólogas, Ayala defendió su derecho aludiendo a la falta de referencia explícita al género, en la Constitución liberal de 1886, donde se declaraba que son ciudadanos "todos los salvadoreńos" mayores de dieciocho ańos ${ }^{3}$. Por consiguiente, insistió en que se le inscribiera en

2 Para más sobre la obra y la labor de esta insigne feminista y las luchas de la década de 1920 véase Sonia Ticas, "Avances y retrocesos en el movimiento sufragista femenino salvadoreño en la década de 1920," Identidades, No. 13, año 8 (San Salvador: Ministerio de Cultura, 2018) 159-174.

3 Véase el caso de México, por ejemplo. Gabriela Cano, "La ciudadanía de las mujeres: Disyuntiva entre la igualdad y la diferencia sexual (México, 1914-1953)", 
el libro de votantes para continuar con sus propósitos de ser candidata a la presidencia. Dada la confusión que se generó con los alegatos presentados, Ayala tuvo que llevar su caso hasta la Corte Suprema, donde se dictaminó que la Constitución se refería a los derechos individuales mas no a los políticos bajo los cuales ella buscó amparo y por tanto se le denegó su petición (“La Corte Suprema” 1 y 8).

Ciertamente, en el terreno legal estos conceptos se prestaban a distintas interpretaciones, pues comúnmente se equiparaban los derechos individuales con los políticos. No obstante, el veredicto de la Corte Suprema era de esperarse en la sociedad patriarcal salvadoreña, donde reinaba el sobreentendido cultural de que las mujeres estaban excluidas del ejercicio de los derechos políticos (Cáceres Prendes 271). Los magistrados, de hecho, concluyeron que la Constitución se refería al sexo masculino exclusivamente, ya que en los tiempos en que fue redactada la mujer estaba en una posición jurídica inferior a la del hombre ${ }^{4}$.

Lanzar una candidatura presidencial parece haber sido una táctica por parte de la intrépida Ayala para promover sus causas mientras contaba con la atención de la prensa. Es más, elaboró una plataforma que, según lo que se reportó, abarcaba un ambicioso programa de reivindicaciones femeninas. Algunos periodistas la calificaron de "prolija exposición de innovaciones radicales a favor de la mujer" (Archivo, "Doña Prudencia Ayala"), aunque también incluyó el apoyo a los sindicatos, la honradez en la administración pública, el control de la distribución y el consumo del alcohol, el respeto por la libertad de culto y el reconocimiento de los hijos ilegítimos (Consalvi 42). Pronto se formaron algunos grupos de apoyo a su candidatura como el Comité Ayalista de Santa Ana y el de San Vicente, que reportaron 729 firmantes con presencia de propagandistas en varias ciudades del país (Archivo, "Minuta" y "Comité Departamental"). A su vez, grupos como el "Círculo Femenino Tecleño" respaldaron su campaña en defensa de los derechos de la mujer, como se puede constatar con su patrocinio de una de sus conferencias (Archivo,

en Martha Moscoso, ed., Palabras del silencio: Las mujeres latinoamericanas y su historia (Quito, Ediciones ABYA-YALA, 1995).

4 Una correspondencia entre un miembro del cuerpo ejecutivo, Manuel V. Mendoza, y el alcalde capitalino se encuentra en el Archivo de Prudencia Ayala. MUPI, 29 de octubre de 1930. Existen copias asimismo del pedido oficial de Ayala y sus respectivos argumentos fundamentados en la constitución. 
"Invitación a una conferencia"). Asimismo, el connotado intelectual y diplomático Alberto Masferrer hizo público su apoyo exponiendo que Prudencia Ayala "defiende una causa justa y noble, cual es el derecho de la mujer a ser elector y ocupar altos puestos. Su programa de gobierno no es inferior en claridad, sentido práctico y sencillez, al de otros candidatos que se toman en serio" (cit. en Consalvi 44). Todo lo anterior revela que esta feminista era también una política perspicaz.

$\mathrm{Al}$ ver cerradas las puertas hacia una candidatura, Ayala no dejó dudas de sus intenciones de seguir labrando el camino de los derechos femeninos (Archivo, "Carta abierta" 1). Tras la negativa de las cortes se dirigió a la Asamblea Legislativa en junio de 1931, solicitando que se enmendara el Código Civil ya que bajo su estado actual la mujer estaba completamente desamparada ante la ley (Archivo, "En pro de los derechos").

Las acciones de Ayala le dieron aliciente a múltiples otras mujeres para demostrar sus capacidades en la cosa pública. De hecho, se evidencia en la prensa que la actividad política femenina de fines de esta década fue significativa. Mujeres de distintos sectores se aliaron con el Partido Laborista que Masferrer y los unionistas terminaron respaldando. Sociedades como Esfuerzo Femenil prestaron gran apoyo organizativo y mujeres de sectores diversos hicieron campaña pronunciando discursos a favor del candidato laborista, contribuyendo con ello a su victoria electoral (Recinos 1; "Actividad electoral" 1). Ninguna de estas mujeres, sin embargo, se destacó de la forma radical y transgresora en que lo estaba haciendo Ayala, poniendo en tela de juicio las leyes establecidas para su género.

Aunque Ayala luchó primordialmente en el terreno regional y nacional, apoyaba sus argumentos haciendo referencia a los avances del movimiento sufragista internacional. Si bien no hay evidencia de que colaborara con los esfuerzos de la representante salvadoreña de la CIM, sí elogió la labor de las feministas en la VI Conferencia Panamericana en la Habana de 1928, en la cual se creó dicha comisión ("Entrevista" 1 y 8). Asimismo, en su conferencia pronunciada en octubre de 1930 se refirió al papel que la delegación guatemalteca había desempeñado en el susodicho encuentro, abogando por los derechos políticos femeninos en el frente internacional ("Conferencia” 3). Guatemala ya contaba con una influyente presencia en estos congresos. De hecho, fue un delegado guatemalteco, Máximo Soto Hall, quien introdujo por primera vez, en 
la V Conferencia Panamericana, realizada en Chile en 1923, una propuesta sobre la igualdad de derechos políticos y civiles que intensificó la movilización de las feministas chilenas y culminó en una resolución para seguir estudiando el caso y además permitir delegadas feministas en dichos congresos (Towns 790).

Tales referencias entusiastas sobre las actividades en pro de las mujeres del continente cobraban importancia tanto en Guatemala como en El Salvador, donde las circunstancias políticas habían coartado los esfuerzos feministas a lo largo de la década de $1920^{5}$. Ayala se quejaba, por ejemplo, de que si bien algunas mujeres lograron incursionar en carreras como el derecho, no les era permitido ejercer ("Conferencia" 3); sin embargo, vislumbraba ya el camino hacia la igualdad de derechos. Frente a la situación imperante, Ayala, como Guillén Rivas, era consciente de que se necesitaba del empuje de legisladores y juristas reconocidos que apoyaran resoluciones a su favor en el marco internacional, lo cual facilitaría sus demandas a nivel nacional ${ }^{6}$. La creación de la CIM y su plataforma de derechos femeninos, a fin de cuentas, le sirvió para fundamentar los alegatos que presentó en la solicitud de su ciudadanía, aunque la interpretación que los ministros de la Corte Suprema le dieron a la constitución salvadoreña la dejó sin amparo legal.

El caso de Ayala puso en evidencia las profundas estructuras patriarcales en la sociedad salvadoreña. Si bien para los reformistas de tradición unionista como Alberto Masferrer, que promovían la emancipación femenina, resultaba natural respaldar el voto de las mujeres, para la mayoría de la sociedad la igualdad de derechos representaba un enorme peligro social. En cuanto a los partidos políticos afines a la causa sufragista, estos habían evidenciado que las feministas estaban prestas a contribuir a la forja de la democracia sin el reconocimiento legal de su ciudadanía,

5 En su tesis doctoral, Patricia Faith Harms abunda sobre los desafíos que vivió el movimiento feminista en Guatemala, liderado por la Sociedad Gabriela Mistral. "Imagining a Place for Themselves. The Social and Political Roles of Guatemalan Women, 1871-1954", (Arizona State University, mayo de 2007).

6 En su conferencia, Ayala menciona al guatemalteco Carlos Salazar, líder de la delegación, como un aliado y Guillén Rivas al eminente jurista Gustavo Guerrero, presidente de la Liga de Naciones en 1929-1930, "Inter-American Commission of Women, Doris Stevens' Papers", Correspondence and Office Files. Salvador: María Alvarez de Guillén Rivas, 1928-1935. Este último luego fungiría como el primer presidente de la Corte Internacional de Justicia. 
lo cual hacía la postergación de sus demandas una práctica normal. De modo que una serie de condiciones tanto políticas como socioculturales detuvieron el avance de las luchas por la obtención del voto femenino en este momento histórico crucial. No obstante, las hazañas libradas por figuras como Prudencia Ayala, al insistir en el voto, crearon mayor consciencia sobre toda la gama de injusticias que sus congéneres padecían.

\section{La Comisión Interamericana de Mujeres en la déCADA de I930}

Mientras Prudencia Ayala sacudía de forma radical los cimientos sexistas de la sociedad salvadoreńa, María Solano Álvarez de Guillén Rivas operaba en el frente internacional como delegada de la CIM. Al entrar la década de 1930, este organismo tuvo a su cargo estudiar el estatus legal de las mujeres en las naciones participantes con el fin de abogar por el reconocimiento de sus derechos políticos. Sus primeras gestiones se orientaron hacia el tema de la nacionalidad, logrando que varios países, incluso El Salvador, acataran los acuerdos alcanzados para que las mujeres no perdieran tal derecho al casarse con extranjeros. Este representaría el primer logro internacional de la organización (CIM/OEA, "A Brief History” 3). Luego tornarían su enfoque al sufragio femenino, dándole el empuje necesario para que más naciones lo otorgaran. Lograron, por ejemplo, que para 1937 se estableciera un comité en la Liga de las $\mathrm{Na-}$ ciones que examinara el estatus legal de las mujeres (Miller 107). Para avanzar en su agenda se requería, no obstante, de un fuerte contingente femenino capaz de ejercer presión en los diversos países participantes. La correspondencia entre la presidenta de la CIM, Doris Stevens, y Guillén Rivas entre 1928 y 1935 revela las distintas estrategias, tales como promover sus actividades en la prensa y buscar aliados entre los políticos, que emplearon las representantes en sus respectivos países para alcanzar sus objetivos (Inter-American Commission of Women 61-73).

El primer estudio que Guillén Rivas preparó fue un diagnóstico general sobre la situación jurídica de las salvadoreñas, cuyos resultados fueron presentados junto al de otras naciones en la VII Conferencia Internacional Americana efectuada en Uruguay en 1933 (CIM, Informe 2-6). En dicho estudio, reportó básicamente lo que ya Prudencia Ayala había señalado sobre el desamparo legal bajo el cual vivían sus compatriotas, con leyes 
patriarcales que no les reconocían una identidad propia al someterlas por completo al control del marido u otras figuras masculinas (Archivo, "En pro de los derechos"). Una diferencia significativa entre estas dos figuras es que mientras Ayala ejercía una libertad plena y contaba con la atención de la prensa, Guillén Rivas operaba dentro de la oficialidad, dependiendo de funcionarios del gobierno para recopilar información y buscar aliados de acuerdo con las directrices recibidas de la CIM (Inter-American Commission of Women 61-73). Estos supuestos aliados, no obstante, actuaban según los designios del gobierno que representaban y no necesariamente velaban por los intereses de las mujeres. Tal proceder quedaría comprobado en la década de 1930.

El gobierno que se instaló por un golpe de Estado en diciembre de 1931 se apropiaría del tema del sufragio para su beneficio. En esta década, este tema pasó de las manos de líderes sufragistas a las de políticos que vieron en las mujeres un asidero que podría garantizar la estancia en el poder del líder a quien rendían pleitesía en las redes clientelistas que se fueron tejiendo (Ching 135-139).

LA DICTADURA MARTINISTA Y EL SUFRAGIO FEMENINO EN EL CONTEXTO NACIONAL E INTERNACIONAL

A lo largo de su primer año de gestión, el gobierno laborista de Arturo Araujo fue agobiado por los efectos de la crisis económica mundial, por lo que las promesas hechas se fueron aplazando, creando con ello un descontento masivo entre la población (Alvarenga et al. 112-131). En diciembre de 1931 el General Maximiliano Hernández Martínez aprovechó el caos para instalarse en el poder por medio de un golpe de Estado. Un mes más tarde, ordenaría la matanza de miles de campesinos que se habían alzado en el occidente del país exigiendo mejores condiciones de vida y trabajo. Durante su régimen, que duraría trece ańos, se vivió un clima represivo que ahogó a la oposición (Ching 175-77). La democracia, pues, sería un sueño iluso, que ahora se suplantaba con el inicio de las dictaduras militares.

El gobierno martinista, establecido de forma ilegal, tuvo que gestionar a nivel internacional para lograr reconocimiento (Alvarenga et al. 
132-33). La presencia oficial de delegados en el Congreso Panamericano de Uruguay en 1933 representó, por tanto, un gesto de legitimidad a medida que distintas naciones iban restableciendo relaciones diplomáticas. En dicha conferencia uno de los delegados salvadoreños fungió de vicepresidente de la Comisión de Derechos Políticos y Civiles de la Mujer, de la cual surgió una resolución para rectificar la cuestión de la pérdida de la nacionalidad para las mujeres al casarse con extranjeros. Tal acuerdo no representaba un peligro para el martinismo; al contrario, proyectaba una imagen de modernidad que favorecía al régimen (Cáceres Prendes 272). Tocante al voto femenino, no obstante, solo cuatro países se expresaron a favor: Cuba, Ecuador, Paraguay y Uruguay y de estos ya el voto era una realidad en Ecuador y Uruguay ${ }^{7}$. La resolución dos, que resultó de las discusiones, estipulaba que cada país determinaría cuándo y cómo expandir la ciudadanía femenina:

Recomienda a los Gobiernos de América que procuren dentro de lo posible, en la más cómoda circunstancia para la situación peculiar de cada una de las Repúblicas, establecer las mayores igualdades entre hombres y mujeres, en todo lo que se refiere a la posesión, goce y ejercicio de los derechos civiles y políticos (Castro et al. 52).

Redactada de esta forma indefinida, dicha resolución otorgaba plena libertad para seguir postergando los derechos ciudadanos que habían exigido las mujeres de la CIM desde su histórico accionar en La Habana en 1928, donde tras protestas y campañas forjaron un espacio para exponer sus demandas (Miller 15). El hecho de que no se tomara una acción en conjunto era particularmente preocupante esta vez, ya que la resolución depositaba la determinación de otorgar o negarles derechos a las mujeres en los gobiernos nacionales. El régimen martinista estaría evaluando si la cuestión convenía en ese momento.

En realidad, no se había esclarecido de forma contundente si las mujeres podían ser calificadas como ciudadanas en El Salvador. Un grupo de la capital se presentó a votar en comicios municipales y en las

7 Para más sobre las maniobras políticas en el seno de estos congresos véase Anne Towns, "The Inter-American Commission of Women and Women's Suffrage, 1929-1945”, Journal of Latin American Studies, Vol. 42, No. 4 (Nov. 2010), $779-807$. 
elecciones presidenciales de 1935 ("En la Constituyente" 1). A algunas se les aceptó su voto de manera honoraria, mientras que a otras se les negó reconocimiento alguno (Cañas Dinarte, "El largo camino" párr. 28). Tales acciones, si no resultaron del legado de Prudencia Ayala probablemente fueron instigadas por elementos ligados al martinismo que esperaban reintroducir el tema del sufragio femenino en momentos en que podría beneficiarles ${ }^{8}$. La elección de 1935 no presentó mayores retos para Martínez, pues maniobró para que se realizara dentro del marco de la legalidad (Ching 175-177; Alvarenga et al. 139-140). Sin embargo, para la elección de enero de 1939, la situación parecía más precaria por tratarse de una reelección que la Constitución prohibía.

Para fines de la década del treinta, el pueblo salvadoreño comenzaba a inquietarse con el despotismo del general Martínez y sus intentos de reelegirse. Estos eran años en que a nivel internacional se combatía el fascismo y se promovía la democracia, lo cual hizo que el régimen planteara una serie de reformas electorales para dar la impresión de estar en sintonía con las exigencias del momento (Cáceres Prendes 272). Es en este contexto y con un claro objetivo de cálculo político que se abrió de nuevo el debate sobre el sufragio femenino al finalizar 1938.

Por otro lado, la CIM, en el Congreso de Lima realizado en diciembre del mismo ańo, ejerció mayor presión para que los países del continente se comprometieran de manera definitiva a garantizarles igualdad de derechos políticos a las mujeres y así toda nación pudiera defender los valores democráticos (Miller 82-86, 108-111). El contexto bélico mundial hacía más urgente tal demanda. Un miembro de la delegación salvadoreña en Lima formó parte de la Comisión sobre los Derechos Civiles y Políticos de la Mujer ("Honrosa parte" 4), lo cual es indicativo de la postura más favorable sobre el voto en esta etapa del martinismo. Al final, la mayoría de las naciones participantes acordaron acatar los acuerdos sobre los derechos políticos femeninos. Este logro, sin embargo, conllevó una concesión, pues la CIM debió renunciar a su autonomía y desde entonces debía pasar a formar parte de los esfuerzos en la defensa

8 Explica Erick Ching que en 1935 el partido Pro-Patria movilizó a un gran número de votantes para legitimar la elección de Martínez. Estas votantes podrían haber formado parte del partido, aunque sus afiliaciones políticas no se han logrado verificar (175-177). 
de la democracia mundial bajo la dirección de la Unión Panamericana y luego la OEA en 1948 (Miller 82-86, 108-111).

El momento era idóneo para que la Asamblea Constituyente de El Salvador discutiera enmiendas constitucionales tocantes al sufragio femenino con el beneplácito de Martínez. Los alegatos que se presentaron esta vez a favor coincidieron con la línea de pensamiento que había regido las discusiones anteriores y que prevalecía en los distintos movimientos sufragistas del continente, principalmente al perfilar a la mujer como promotora de la paz (Miller 105-109). El dictador salvadoreño no dudó en expresar su apoyo exaltando el carácter "incorruptible" de la mujer, la cual en tiempos tan críticos sería buena "defensora de la paz", debido a su "naturaleza pacífica" ("Discurso del Presidente" 7) ${ }^{10}$.

Esta vez se estableció su derecho al sufragio sin mayor oposición, pero faltaba decidir si se le debía imponer restricciones. Semejante a lo sucedido en 1921 con el voto de los diputados unionistas, se acordó por una votación de 27 a favor y 8 en contra que se limitara por edad, estado civil y nivel educativo, por considerarse un ensayo. Solo las mujeres con un grado mínimo de educación primaria que fueran solteras mayores de treinta años y las casadas mayores de veinticinco serían aptas para votar ("En la Constituyente" 1). Se dictaminó, además, que su voto fuera voluntario, mientras que para el elemento masculino este seguía siendo obligatorio.

Con estas restricciones se traslucía la incertidumbre sobre las verdaderas simpatías políticas de este potencial grupo de electores, especialmente en ańos en que el régimen estaba perdiendo apoyo. Uno de los diputados pidió que las leyes secundarias electorales reglamentaran las restricciones, señalando que "si los resultados son buenos, puede reformarse la ley con facilidad o ampliar el derecho quitando o disminuyendo las restricciones" ("En la Constituyente" 1). Estos "buenos" resultados, por supuesto, se referían a los que beneficiaran al dictador. El caso es que se arrojaba duda sobre la validez del voto femenino. Si no resultaba en

9 Anne Towns señala que en realidad la CIM no contaba con mucho poder político al estar bajo la sombra de la Unión Panamericana desde su creación (799).

10 Los debates que se realizaban en otros países eran muy similares. Francesca Miller discute a fondo este tema en el capítulo cinco "Democracy and the Search for Social Justice, 1938-1958" de Latin American Women and the Search for Social Justice (110-149). 
lo esperado, los legisladores fácilmente podrían despojar a las nuevas ciudadanas de su derecho.

El voto cauteloso reveló, a fin de cuentas, una actitud paternalista típica de otros países donde también se instituyó la práctica de restringir el voto femenino, aplicando con esto una doble moralidad (Miller 96-100). Ana Rosa Ochoa, una de las voces feministas más connotadas de la siguiente década, respondió indignada, criticando precisamente el requisito educativo por considerarlo injusto ${ }^{11}$. Al exponer que la mujer estaba en una posición muy desigual a la del hombre, alertó que tomaría ańos antes de que, en esas condiciones, sus congéneres pudieran hacer uso eficaz del voto (Ochoa, "A propósito" 3). De hecho, el censo de 1930 reveló que únicamente un 21\% de las mujeres mayores de 23 años estaba alfabetizado (Myers 6). Esta cifra, además de la forma en que se dio el dictamen, apuntaba a la baja probabilidad de que dentro del martinismo surgiera un verdadero espacio ciudadano para la mujer, como tampoco existía para el ciudadano masculino que no concordaba con la política del dictador.

Las congraciadas del martinismo, por su parte, organizaron una delegación de 400 mujeres que acudió a la casa presidencial en símbolo de agradecimiento al presidente por su "magnánimo" gesto al extenderles su apoyo al sufragio ("La mujer salvadoreña" 4). Este grupo, que actuaba probablemente a instancias del Partido oficial Pro-Patria, ignoró las motivaciones detrás de la política martinista y sus tácticas para legitimar su permanencia en el poder mientras la Constitución prohibiera la reelección.

A fin de cuentas, ni las simpatizantes martinistas ni los votantes masculinos votarían, ya que a última hora el poder legislativo controlado por Martínez enmendó la Constitución estipulando que el presidente sería escogido por la Asamblea Nacional en esta única ocasión porque "así lo exigían los intereses nacionales" (Turcio 425). Por el mismo artículo quedaba exenta la prohibición de reelección y se extendía el cargo a seis años en lugar de cuatro (Ching 181). Por consiguiente, la enmienda constitucional que reconocía el sufragio femenino no llegó a reglamentarse en las leyes electorales secundarias, como se había decidido, porque simplemente no hubo necesidad de dichas leyes (Moreno

11 Ochoa se convertiría en una de las integrantes más combativas de la Liga Femenina en 1948, que llevaría la lucha sufragista a su etapa final. 
15). La historia se repetía de nuevo a casi veinte ańos desde la primera tentativa centroamericana de revestir de derechos políticos a las mujeres.

En la década de 1930, si bien el gobierno de Martínez demostró interés en acatar convenios internacionales, a nivel nacional operó por puro cálculo político al considerar extenderles derechos ciudadanos a las mujeres. Para 1939, estaba claro que mientras Martínez siguiera en el poder no habría ninguna garantía de respetar el sufragio. Sin embargo, la imagen que se intentaba proyectar al mundo era una de modernidad.

EL FIN DEL MARTINATO Y EL AUGE DEL MOVIMIENTO SUFRAGISTA NACIONAL

A principios de la década del cuarenta hubo una serie de cambios con respecto a la incursión femenina en espacios públicos. Por estos años, un mayor número de mujeres ingresó a las universidades, optando por carreras diversas (Loucel 33). Las intelectuales, por su parte, se unieron a redes de escritores centroamericanos para combatir las tiranías de la región. Las mujeres salvadoreñas -como luego lo harían las guatemaltecas en la Revolución de Octubre en 1944 y unos años más tarde, en 1948, las costarricenses- no dudaron en unirse a los movimientos revolucionarios que prometían cambios sociales y políticos (Ordóñez Argüello 11).

Al intentar Martínez cambiar la Constitución para reelegirse, las escritoras Matilde Elena López y María Loucel pusieron en riesgo su vida convocando a las masas a participar en la rebelión cívico-militar que se estaba organizando contra el dictador ${ }^{12}$. Mujeres de distintas capas sociales se unieron a las movilizaciones, entre ellas una huelga de brazos caídos, que por fin acabó con trece años de dictadura en mayo de 1944. Sus acciones provocaron la admiración de la sociedad salvadoreña, que

12 María Loucel (1899-1957) fue maestra de instrucción pública y poeta. Publicó en 1937 su colección Ilapso. En Reseña general de representativos femeninos en el reino de Cuscatlan, El Salvador (1949) recogió la biografía de destacadas mujeres de su época. Matilde Elena López (1919-2010), por su parte, empezó publicando poemas, reseńas y artículos en los periódicos nacionales y se incorporó a asociaciones de escritores centroamericanos. 
las enalteció al nivel de patriotas y mártires (Ordoñez Argüello 11) ${ }^{13}$. Noticias de sus heroicos actos resonaron con organizaciones femeninas de Guatemala y Cuba, con las que estrechaban lazos a través de las actividades de la CIM y que expresaron su solidaridad exigiendo el cese de su persecución ("Asociación cultural de Cuba" 4). Toda esta publicidad les sirvió para llamar la atención sobre sus derechos ciudadanos una vez instaurado un gobierno interino.

Con la caída del gobierno de Martínez, sin embargo, se heredó una tremenda crisis constitucional. Los poderes del Estado, tras presión social, decidieron regir al país bajo la Constitución liberal de 1886 hasta que una nueva Asamblea Legislativa, por elegirse en enero de 1945, discutiera las enmiendas que más urgían (Alvarenga et al. 174). En lo tocante al sufragio, como se constató en la prensa, la cuestión provocó un extenso debate, por lo que se sometió nuevamente a estudio la categoría de ciudadano. Básicamente, se discutía poner en vigencia el artículo que restringía el voto femenino por edad, estado civil y nivel educativo, estipulado en la Constitución promulgada en enero de 1939. Esto, por supuesto, no lo aceptaron quienes luchaban fervientemente por la democracia. Bajo el liderazgo de Loucel, que coordinaría el ala femenina del Partido de Unión Democrática (PUD), se aglutinó el elemento femenino para exigir su derecho al voto irrestricto con la esperanza de ejercerlo en las elecciones presidenciales que se avecinaban.

Con la opinión pública de su lado, esta vez las sufragistas actuaron sin temor, haciendo un llamado a sus compatriotas a exigir que se les reconocieran sus derechos sin cortapisas ("Pedirán voto" 3). Loucel articuló elocuentemente los argumentos, enfatizando la ciudadanía para ambos sexos como un beneficio en la construcción de la nación:

Tiempo es que ya se conozca sin reticencias que la mujer razona, trabaja, lucha y triunfa con igual visión cívica que el hombre. Que se les deje romper las asperezas y los obstáculos para que así el resultado de su compañerismo sea para El Salvador (masculino) o la patria (femenina) la prosperidad nacional ("María Loucel comenta” 9).

13 Loucel sufrió encarcelamiento y López se dio a la fuga, mientras que otras mujeres perdieron su vida (Ordóñez, "De por qué" 11). 
Asimismo, la educadora Helena García Gallont recalcó el ya bien conocido postulado acerca de que, ejerciendo la ciudadanía, las mujeres estarían mejor capacitadas para instruir a los nuevos hijos que le urgían a la patria:

Somos nosotras las mujeres las que educamos a los futuros gobernantes. Si tan delicada y grande responsabilidad fue puesta en nuestras manos por ley divina, cómo lo es la vida del individuo y la educación de los hombres del mañana, con mayor razón nos corresponde el derecho de expresar nuestra voluntad, referente a quién deseamos que rija los destinos de la patria ("Helena García Gallont secunda la protesta” 9).

Sabiendo que tendrían una mayor aceptación, estas feministas crearon un discurso conciliador en el que vincularon armónicamente el rol privado de la mujer madre y compańera con el público de la ciudadana sin que esto representara un peligro a la institución familiar, como se había alertado en ocasiones previas. De esta manera, las salvadoreñas, al igual que las guatemaltecas y costarricenses, eran conscientes de que, desde estos roles típicamente femeninos y sus discursos maternalistas (Rodríguez de Ita 82; Rodríguez Sáenz 52-56), podían alcanzar un mayor número de simpatizantes.

Pese a que grupos de mujeres se manifestaron en diversas partes del país exigiendo el voto sin restricciones, los poderes del Estado dictaminaron mantener las estipulaciones electorales de la Constitución de 1939 emitida bajo Martínez (Castellanos 161-3). Tal decisión provocó una avalancha de nuevas protestas por considerarse indigno el escrutinio al que debían someterse las votantes elegibles ${ }^{14}$. García Gallont puntualizó que con un $80 \%$ de analfabetas, solo una minoría estaría capacitada para votar (3). Las que alzaron su voz urgieron una y otra vez que se reconsiderara dicho dictamen y que se arrancaran desde sus raíces los residuos de martinismo para proteger la frágil democracia que se estaba

Véase como ejemplos los siguientes reportes del Diario Latino: "Desde Atiquizaya se solicita el voto irrestricto para la mujer" (25 de septiembre 1944) 1; "Cartelera Política. La inquietud femenina en la política nacional" (27 de septiembre) 9. Otras mujeres registraron su protesta en La Tribuna, sección "Voz Femenina". Fidelina Ávila, "Por qué se nos niega a las mujeres el derecho de votar" (4 de agosto de 1944) 3 . 
construyendo en el país ("Helena García Gallont secunda la protesta" 9). Sus argumentos tuvieron amplia cobertura en la prensa y contaron con el respaldo de expertos en derecho (Virgil 3).

No obstante, todos los esfuerzos de las sufragistas y su base de apoyo no hicieron desistir a los ministros de gobierno de su decisión. El presidente interino, Andrés I. Menéndez, recalcó que sería la próxima Asamblea Nacional Constituyenteq, por elegirse en enero de 1945, la que decidiría sobre el asunto de las restricciones ("Hubo Manifestaciones" 1). Por el momento, las votantes elegibles no tuvieron otra opción viable más que acatar este dictamen y posteriormente dedicarse a reunir los documentos requeridos para lograr su inscripción como ciudadanas y poder votar en las elecciones de 1945 ("Sumario" 2106)

La gran ironía fue que, con un nuevo golpe militar ejecutado a fines de octubre de 1944 por elementos martinistas y la subsiguiente represión que se desató, se vino abajo todo afán democrático. Las tan anticipadas elecciones se realizaron en medio del fraude y con un solo candidato, que restauró la Constitución de 1939 (Castellanos 169). La persecución de los disidentes se recrudeció en el contexto de la Guerra Fría, que puso a países como El Salvador en el centro de las pugnas anticomunistas ${ }^{16}$.

Fue en la Guatemala revolucionaria de Juan José Arévalo (19451951) y Jacobo Arbenz (1951-1954) donde Matilde Helena López y la comunidad de exiliados salvadoreños encontrarían un espacio propicio para desarrollar una agenda de reformas sociales y defensa de la democracia $^{17}$. En la página femenina del Diario del Mediodía, fundado por salvadoreños, López llamaba la atención sobre los avances de las mujeres en el mundo e incitaba a las guatemaltecas a levantar la bandera del

15 Una serie de noticias apuntan a las dificultades que encontraron muchas mujeres para reunir los documentos requeridos, en particular los certificados de escolaridad primaria.

16 Entre 1944 y 1954, Matilde Helena López colaboró con los exiliados salvadoreńos y el Partido Comunista en Guatemala (Dalton 443-446). Con el golpe realizado contra el gobierno de Jacobo Arbenz en 1954 tuvo que irse al exilio a Ecuador, donde completó la licenciatura en Filosofía y Letras (Cañas Dinarte, Diccionario 163).

17 María Vilanova de Arbenz, la esposa salvadoreńa del presidente Jacobo Arbenz, destacaría también por su agenda de reformas sociales y su defensa de los derechos políticos femeninos (Harms 342-44). 
feminismo para exigir la plenitud de derechos en todos los sectores de la vida privada y pública ("Mujer nueva" 7).

En Guatemala se les otorgó el sufragio únicamente a las mujeres alfabetizadas en marzo de 1945. Este grupo, considerado tradicionalmente conservador según el parecer del gobierno de Arévalo, no impactaría el proyecto revolucionario pues representaba un bloque mínimo del electorado. Patricia Harms señala que esa decisión fue contraproducente, ya que dejó fuera a las mujeres de la clase proletaria que sí apoyaban la causa revolucionaria y por tanto la defenderían de las amenazas internas y externas $(298-9,426)$. En 1947, se trajo nuevamente a colación la cuestión del voto cuando se realizó un seminario de la CIM con la participación de decenas de delegadas de diversas organizaciones femeninas de todo el continente (Harms 302-304). Entre ellas se encontraba López al frente de uno de los comités.

El contexto bélico mundial hacía más urgente la colaboración panamericanista y las mujeres que se dieron cita en Guatemala se aprestaron para exigir el voto como medio para forjar la paz (Miller 128-9). En el discurso de apertura del seminario, la escritora Malin D'Echevers, Secretaria General del Comité Organizador, declaró enfáticamente el papel clave que desempeńaba la mujer en esta cruzada y la urgencia de investirla de derechos:

la cooperación amplia de la mujer habrá de ser determinante para promover la verdadera democracia en el hemisferio, queremos que sean reconocidos en toda América nuestros derechos civiles, políticos y sociales, y que no se nos niegue el acceso a cargos de responsabilidad y a puestos directivos (19-20).

Para la época, una decena de países latinoamericanos aún no reconocía los derechos políticos femeninos, por lo que se les instó a hacerlo cuanto antes, según la recomendación de la Carta de las Naciones Unidas (D’Echevers 30; Harms 306; Towns 787).

Seis comités se dieron a la tarea de formular resoluciones enfocadas en los objetivos del congreso. En su capacidad de delegada por el Frente Femenino de El Salvador, Matilde Helena López discurrió sobre los acuerdos del Acta de Chapultepec (1945), en lo concerniente a la erradicación del fascismo y la defensa de la paz y democracia entre los 
pueblos de las Américas (López 99-102). Con este fin, presentó varias resoluciones en colaboración con su homóloga guatemalteca, María del Carmen Vargas, orientadas al desarme continental (López y Vargas 3840; Harms 307). Tras una semana de intensos debates y resoluciones, el seminario concluyó con la creación de la Federación de Mujeres de las Américas, que continuaría fomentando una cultura democrática en el hemisferio (Harms 314).

Estos encuentros muestran cómo las feministas de la época unieron lazos para combatir fuerzas globales que amenazaban con postergar aún más la reivindicación de sus derechos. Aunque en el marco de la Guerra Fría sus objetivos podrían considerarse idealistas, estos congresos les permitieron definir de forma contundente los distintos espacios ciudadanos en los que podrían integrarse para lograr mayor visibilidad.

\section{LA RECTA FINAL}

Mientras los exiliados salvadoreños en países como Guatemala avanzaban en las luchas por la justicia social, los esfuerzos de aquellos que luchaban por la democracia en El Salvador finalmente empezaron a dar fruto. En diciembre de 1948, un grupo de jóvenes militares progresistas dio un golpe de Estado decisivo que habría de desencadenar un movimiento político que se catalogó de revolución y que, tras redactar un proyecto constitucional a la altura de los tiempos modernos, culminó con elecciones en marzo de 1950 (Cáceres Prendes 272).

En 1948, también se logró retomar la causa de los derechos de las mujeres con la creación de la Liga Femenina Salvadoreña, que se perfiló como una entidad independiente que velaba por el bienestar social y el amparo jurídico de la mujer (Moreno 16). Las feministas de la Liga, entre las que se contaban sufragistas de larga trayectoria como María Solano Álvarez de Guillén Rivas, se organizaron para recordarles a los redactores de la nueva Constitución que su demanda de gozar de una ciudadanía plena todavía seguía pendiente. El Salvador era signatario del convenio internacional acordado en la IX Conferencia Panamericana en Bogotá, que les garantizaba la igualdad de derechos políticos y civiles a las mujeres (CIM/OEA, History 43). Con el fin de llegar hasta la recta 
final en la lucha sufragista, hicieron un amplio llamado a sus compatriotas a unirse a su movimiento a través de la radio y su publicación Heraldo Femenino (Moreno 16; García Castro 182-185). Algunas de las integrantes de la Liga optaron por aliarse nuevamente con el PUD, conocido ahora como PRUD (Partido Revolucionario de Unificación Democrática), que prometía adoptar la plataforma feminista de la Liga (Cáceres Prendes 273).

Sin mayor oposición, se levantaron finalmente las restricciones al voto femenino a través de La Ley Transitoria Electoral emitida en enero de 1950, declarando que "son ciudadanos todos los salvadoreños sin distinción de sexo mayores de dieciocho años" (Samayoa 116). Tal reglamentación permitió a las mujeres votar de forma masiva en las elecciones de marzo de 1950, sobrepasando a los votantes masculinos ("En San Salvador" 1). No obstante, en la misma ley se estipuló que solo los salvadoreńos varones podrían optar a cargos públicos (Samayoa 117), injusticia que no dejaron de protestar las portavoces de la Liga Femenina. El prolijo discurso de una representante ante la Asamblea Legislativa hacía hincapié en lo retrógrado de tal acción:

¿Cuáles son las causas de la oposición a reconocer nuestros derechos? En primer lugar el temor pueril a las grandes innovaciones; el miedo de asumir responsabilidades para el futuro y en una palabra, la cobardía que ha sido siempre un obstáculo para el progreso (Ochoa, "Exposición" 2).

Al promulgarse la Constitución política en septiembre de 1950, quedó codificado el derecho no solo a votar sin restricción alguna, sino también a ser elegidas (Constitución de la República, artículo 23).

A pesar de todos estos logros legislativos, aún restaba por verse lo que implicaba la absoluta igualdad ante la ley en años posteriores, cuando el movimiento de mujeres se vio absorbido por el PRUD, el nuevo partido oficial en el poder, con el que simpatizaba un buen número de feministas desde su primera configuración en 1944. 


\section{Conclusiones}

El camino hacia el voto femenino en El Salvador, como en otros países del continente, dependió de muchos factores. Dada la represión que sufrieron las organizaciones femeninas y las líderes feministas salvadoreñas en los años veinte, se dificultó sostener un movimiento cohesivo en pos de derechos políticos a largo plazo. Las feministas del país aprovecharon algunas coyunturas políticas nacionales y los acuerdos que gestionó la CIM, pero cuando parecía que por fin alcanzarían el anhelado reconocimiento, se imponía algún obstáculo en su camino. Pronto se hizo evidente que la expansión del sufragio dependía de algún objetivo político específico. Así había sucedido en el caso de Ecuador en 1929, donde el derecho a sufragio lo otorgó una coalición conservadora, pensando que sería fácil manipular a las mujeres, y de forma semejante ocurrió en Guatemala en 1945, donde se le dio poca importancia. En El Salvador, así como en la mayoría de los países del continente, no fue hasta después de la Segunda Guerra Mundial, cuando el sufragio femenino se dio en circunstancias más democráticas y con estipulaciones de absoluta igualdad, aunque las manifestaciones de dicha práctica en cada país tendrían que examinarse (Miller 96-99).

Las mujeres de todas las etapas de las luchas sufragistas tuvieron que alzar su voz de protesta, diseñar acciones contundentes, crear alianzas y usar los medios masivos para crear conciencia de su causa y generar una opinión pública favorable. Las que lograron operar dentro de la oficialidad, en las alas femeninas de los partidos o como delegadas de la CIM, no siempre vieron sus esfuerzos coronados. Por ello, se requirió de múltiples estrategias y de condiciones políticas favorables a la democracia tanto a nivel nacional como internacional para que la lucha sufragista diera los frutos anhelados. A manera de conclusión, concordamos con Deniz Kandiyoti al declarar que las mujeres, no teniendo otras alternativas, "negocian con el patriarcado y el paternalismo, luchando en contra de las circunstancias, pero también tomando las mejores decisiones en dadas circunstancias" (traducción propia, cit. en McDowell 86). Las feministas de la primera mitad del siglo veinte tuvieron que navegar múltiples espacios e identidades en contextos variados y es así como fueron adquiriendo mayor conciencia de las fuerzas sociales, culturales y políticas que operaban en su contra. 
Bibliografía

Alvarenga, Patricia. Cultura y ética de la violencia. El Salvador, 18801932. Costa Rica, Editorial Universitaria Centroamericana-Educa, 1996.

ET AL. Historia de El Salvador. Tomo II. San Salvador, Ministerio de Educación, 1994.

"Actividad electoral en la República”. Diario Latino, 23 de noviembre, 1931, p. 1.

Archivo Prudencia Ayala, Museo de la Palabra y la Imagen (MUPI), San Salvador, El Salvador. Consultado en julio de 2015.

. "Carta abierta a los salvadoreños". La Época, 25 de noviembre, 1930 , p. 1.

. "Comité Departamental de San Vicente, 'Fidelidad y Patriotismo' Pro-Prudencia Ayala”. Hoja volante. Imprenta Castillo S.V. San Vicente, 30 de junio, 1930, s/p.

. "Dońa Prudencia Ayala va a fundar el gran partido feminista salvadoreño". La Época, 5 de julio de 1930, s/p.

. "En pro de los derechos individuales de la mujer ante el mundo civilizado en la Augusta Asamblea Legislativa Nacional de la República de El Salvador en la América Central: La mujer salvadoreña defiende sus derechos". Boletín. Santa Ana, Imprenta. R. Delgado M., 16 de junio, 1931, s/p.

"Invitación a una conferencia de Prudencia Ayala patrocinada por el Círculo Femenino Tecleño". Hoja volante. Santa Tecla, Imprenta Tecleña, 24 de octubre, 1930, s/p.

. "Minuta". Comité Ayalista, s/f, s/p.

. "Resulta una candidata a la presidencia. La Prudencia Ayala también aspira a la sabrosa guayaba". Diario de Santa Ana, 28 de abril de 1930, s/p.

“Asociación cultural de Cuba se interesó por María Loucel”. Diario de Hoy, 19 de mayo, 1944, p. 4.

Ayala, Prudencia. "Conferencia de los derechos políticos de la mujer". Diario del Salvador, 29 de octubre, 1930, p. 3. 
Cáceres Prendes, Jorge. "Género, ciudadanía y cultura política en El Salvador: 1930-1959". Identidades nacionales y estado moderno en Centro América. Arturo Taracena y Jean Piel (eds.), San José, FLACSO, 1995, pp. 269-281.

Cañas Dinarte, Carlos. Diccionario de autoras y autores de El Salvador. San Salvador, CONCULTURA, 2002.

"El largo camino hacia el voto femenino". Servicio Informativo Ecuménico y Popular, 3 de julio, 2017. Web. Consultado el 15 de julio de 2021. Disponible en: https://ecumenico.org/el-largo-camino-hacia-el-voto-femenino-2.

Casaús Arzú, Marta. "El binomio degeneración-regeneración en el positivismo y espiritualismo de principios del siglo XX". El lenguaje de los ismos: algunos conceptos de la modernidaden América Latina. Marta Elena Casaús Arzú (coord.), Ciudad de Guatemala, F\&G Editores, 2010, pp. 157-202.

Castellanos, Juan Mario. El Salvador 1930-1960. San Salvador, CONCULTURA, 2002.

Castro, Héctor David et Al. Informes de la Delegación de El Salvador a la VII Conferencia Panamericana celebrada en Montevideo del 3 al 26 de diciembre de 1933. San Salvador, Imprenta Nacional, 1934.

Ching, Erick. "El clientelismo y la política bajo Martínez: 1931-1939”. Las masas, la matanza y el martinato en El Salvador. Erik Ching, Carlos López Bernal y Virginia Tilley, San Salvador, UCA Editores, 2007, pp. 139-185.

Comisión Interamericana de Mujeres/Organización de los Estados Americanos. "A Brief History of the Inter-American Commission of Women". oas.org. Web. Consultado el 5 de junio de 2015. Disponible en: http://www.oas.org/en/cim/docs/BriefHistory[EN].pdf . History of the Inter-American Commission of Women, 19281997. Washington, D.C., CIM/OEA, 1999.

. Informe de la Comisión Interamericana de Mujeres sobre los derechos politicos y civiles de la mujer para la acción de la Séptima Conferencia Internacional Americana de acuerdo con la resolución de la sexta conferencia. Washington D.C, Comisión Interamericana de Mujeres, 1933, pp. 2-6. 
Consalvi, Carlos Enríquez. "Prudencia Ayala, Hija de la centella". Trasmallo, Museo de la Palabra y la Imagen, N4, 2009, pp. 41-44.

Constitución Política de la República de Centro América. Tegucigalpa, Tipografía Nacional, 1921.

Constitución de la República de El Salvador. México, D.F., UNAM, Instituto de Investigaciones Jurídicas, 1994.

Dalton, Roque. Miguel Mármol. Los sucesos de 1932 en El Salvador. San Salvador, UCA Editores, 1997.

"Discurso del Presidente Martínez ante la Asamblea Constituyente". Diario Nuevo, 21 de noviembre, 1938, p. 7.

D’ Echevers, Malin. “Introducción”. Memoria del Primer Congreso Interamericano de Mujeres, celebrado en la capital de Guatemala del 21 al 27 de agosto de 1947, Ciudad de Guatemala, Tipografía Nacional, 1947, pp. 17-21.

"En la Constituyente se otorgó ayer el derecho del voto". Diario El Mundo, 6 de diciembre, 1938, p. 1.

"En San Salvador y en otros lugares votaron más mujeres que hombres". Tribuna Libre, 29 de marzo, 1950, p. 1.

"Entrevista de Prudencia Ayala con el Sr. Presidente". Diario del Salvador, 20 de julio, 1930 , pp. 1 y 8.

García Gallont, Helena. "Carta abierta al Excelentísimo señor Presidente provisorio de la república abogando por los derechos naturales de la mujer". La Tribuna, 27 de septiembre, 1944, p. 3.

García Castro, Cristina. "La Liga Femenina Salvadoreña: un acercamiento a los discursos en la década de 1950". Identidades, Ministerio de Cultura de El Salvador, №13, julio-diciembre, 2018, pp. 176-190.

Harms, Patricia. Imagining a Place for Themselves. The Social and Political Roles of Guatemalan Women, 1871-1954. Tesis doctoral, Arizona State University, mayo de 2007.

"Helena García Gallont secunda la protesta de la Poetisa María Loucel". Diario Latino, 16 de julio, 1944, p. 9.

"Honrosa parte toma nuestra delegación a la Conferencia Panamericana de Lima”. La República, 27 de diciembre, 1938, p. 4.

"Hubo Manifestaciones pidiendo el voto femenino irrestricto". Diario Latino, 27 de septiembre, 1944, p. 1. 
Inter-American Commission of Women. "Doris Steven's Papers. Correspondence and Office Files. Salvador: María Alvarez de Guillén Rivas, 1928-1935. MC 546, folder 90.3”. Harvard Library. Web. Consultado el 15 de enero de 2020. Disponible en: https://iiif.lib. harvard.edu/manifests/view/drs:52898799\$4i.

"La Corte Suprema de Justicia rechazó el amparo pedido por Dña. Prudencia Ayala". Diario del Salvador, 23 de noviembre, 1930, pp. 1 y 8.

"La mujer salvadoreńa agradece al presidente el derecho de sufragio que se le acaba de conceder". Diario Nuevo, 8 de diciembre de 1938, p. 4.

Lavrín, Asunción. "La génesis del sufragio femenino en América Latina". Un siglo de luchas femeninas en América Latina. Eugenia Rodríguez Sáenz, San José, Editorial de la Universidad de Costa Rica, 2005, pp. 3-22.

López, Matilde Helena. "Mujer Nueva", Diario del Mediodía, 3 de julio, 1945.

. "Problemas de política interamericana". Memoria del Primer Congreso Interamericano de Mujeres, celebrado en la capital de Guatemala del 21 al 27 de agosto de 1947. Ciudad de Guatemala, Tipografía Nacional, 1947, pp. 99-102.

López, Matilde Helena y María del Carmen Vargas. "Comisión $N^{\circ}$. 4. Problemas de política interamericana”. Memoria del Primer Congreso Interamericano de Mujeres, celebrado en la capital de Guatemala del 21 al 27 de agosto de 1947. Ciudad de Guatemala, Tipografía Nacional, 1947, pp. 37-40.

Loucel, María. "Reseña general de representativos de Cuscatlán”. Biblioteca Nacional de El Salvador, sin datos editoriales.

Magaña de Fortín, Victoria. Importancia de la mujer. Artículos publicados en la prensa por OLIMPIA. San Salvador, 1910.

"María Loucel comenta las restricciones al voto de la mujer". Diario Latino, 12 de julio, 1944, p. 9.

McDowell, Linda. Gender, Identity and Place. Understanding Feminist Geographies. Mineápolis, University of Minnesota Press, 1999.

Miller, Francesca. Latin American Women and the Search for Social Justice. Londres, University Press of New England, 1991. 
"Latin American Women and the Transnational Arena". Women, Culture and Politics in Latin America. Emily Bergmann et. al., Berkeley, California, University of California Press, 1990. pp. 10-25. Moreno, Elsa. Mujeres y politica en El Salvador. San José, FLACSO, 1997. Myers, Yolanda. La mujer ante el derecho civil y politico. Tesis de licenciatura, Universidad Nacional de San Salvador, 1952.

Ochoa, Ana Rosa. "A propósito del voto femenino". Diario Nuevo, 8 de diciembre, 1938, p. 3.

. "Exposición presentada a la honorable asamblea constituyente". Heraldo Femenino, 14 de julio, 1950, pp. 1-2.

Ordoñez Argüello, Alberto. "De por qué la mujer salva a El Salvador". La Prensa Gráfica, 7 de junio, 1944, p. 11.

. "Pedirán voto para las mujeres". La Tribuna, 4 de julio 1944, p. 3.

Recinos, Luis Felipe. "Actualidad Política". Diario Latino, 2 de septiembre, 1931, p. 1.

Rodríguez de ITA, GuAdalupe. Mujeres abriendo brecha en la primavera guatemalteca (1944-1954). Ciudad de México, Nostromo, 2012.

Rodríguez SÁEnz, Eugenia. "Madres, reformas sociales y sufragismo: el Partido Comunista de Costa Rica y sus discursos de movilización política de las mujeres (1931-1948)". Cuadernos Inter.c.a.mbio sobre Centroamérica y el Caribe, Vol. 11, N¹, 2009, pp. 45-77.

SAMAYOA, Mario. "Legislación y procesos electorales en El Salvador". Biblioteca Jurídica Virtual del Instituto de Investigaciones Jurídicas de la UNAM. Web. Consultado el 15 de abril de 2015. Disponible en: https://archivos.juridicas.unam.mx/www/bjv/libros/3/1045/5.pdf

"Sumario. Poder Legislativo, Poder Ejecutivo y Poder Judicial". Diario Oficial. El Salvador, Tomo 137, Nº156, 12 de julio, 1944, p. 2106.

Threlkeld, Megan. "The Panamerican Conference of Women, 1922: Successful Suffragists Turn to International Relations”. Diplomatic History, vol. 31, N5, 2007, pp. 801-828.

Towns, Anne. "The Inter-American Commission of Women and Women's Suffrage, 1929-1945”. Journal of Latin American Studies, vol.42, $\mathrm{N}^{\circ}$ 4, 2010, pp. 779-807. 
Turcio, Roberto. "Los años del general en El Salvador". La República 1924-1999, Tomo II, San Salvador, Fomento Cultural, Banco Agrícola, 2000.

Uriarte, Juan Ramón. “Maternidad cívica. El voto femenino”. Repertorio Americano, San José, Costa Rica, 1 de marzo 1921, p. 201.

Vásquez Monzón, Olga. Mujeres en público. San Salvador, UCA Editores, 2014.

Virgil, José Alfredo. "Consideraciones jurídico-legales del voto femenino”. Diario Latino, 27 de julio de 1944, p. 3.

Recepción: 15-03-21

Aceptación: 08-06-21 